\title{
European Communities - Anti-Dumping Duties on Imports of Cotton-Type Bed Linen from India (AB-2000-13, WT/DS141/AB/R:DSR 2003: III, 965): Recourse to Article 21.5 of the DSU by India
}

\author{
GENE M. GROSSMAN* \\ Princeton University \\ ALAN O. SYKES* \\ University of Chicago
}

\section{Introduction}

This chapter addresses the dispute brought to the World Trade Organization (WTO) by India concerning anti-dumping duties imposed by the European Communities (EC) on cotton-type bed linen. An earlier complaint brought by India challenged the anti-dumping duties on a number of points, including the EC practice of "zeroing" for the computation of dumping margins (which had the effect of assigning a negative dumping margin a weight of zero when computing a weighted average dumping margin). ${ }^{1}$ India prevailed in that dispute, ${ }^{2}$ and the EC responded with Council Regulation (EC) No. 1644/2001, amending the original anti-dumping measure on bed linen from India. India was of the view that the amended measure did not comply with EC obligations under the WTO Anti-dumping Agreement, and brought

* This chapter was prepared for the American Law Institute project on "The Principles of WTO Law." We thank Kathy Spier for thoughtful assistance.

1 The decision in the earlier proceeding is the subject of an earlier chapter in this series. See Janow and Staiger (2003).

${ }^{2}$ See European Communities - Anti-Dumping Duties on Imports of Cotton-Type Bed Linen from India, WT/DS141/AB/R, adopted March 12, 2001. 
the proceeding under Art. 21.5 of the DSU that is the subject of this chapter.

Several issues were raised before the Art. 21.5 Panel, but only three issues reached the Appellate Body. First, India argued that although the EC had corrected the "zeroing" problem, it had failed to ensure that injury attributable to "other factors" had not wrongly been attributed to dumped imports, in violation of Art. 3 of the Anti-dumping Agreement. Second, India argued that in conducting its revised injury analysis, the EC violated Art. 3 when it presumed that all imports from exporters not individually investigated were "dumped," even though 53\% of the imports from exporters that were individually investigated were found not to have been dumped once the "zeroing" method of calculation was abandoned. Finally, India argued that the EC had not properly considered certain factors bearing on injury that it was required to consider under Art. 3.

The Appellate Body ruled in favor of the $\mathrm{EC}$ on the first issue, holding that it had been resolved definitively in the original proceeding. It ruled in favor of India on the second issue, however, concluding that imports from producers not individually investigated could not be presumed to be dumped for purposes of injury analysis when some of the individually investigated exporters were not dumping. On the third issue, the Appellate Body upheld the finding against India by the Panel, deferring to its resolution of what the Appellate Body considered an essentially factual issue.

From a legal perspective, the Appellate Body's decision on the first issue raises some interesting questions about the proper scope of res judicata, issue preclusion, and waiver in WTO jurisprudence, but provides few answers. The case breaks new ground with respect to the second issue noted above as well, and we quibble somewhat with the Appellate Body's legal and logical reasoning there. Finally, the Appellate Body's deference to the Panel on the third issue seems appropriate, as best we can determine.

From an economic perspective, we find the procedural issue to be an interesting one. Little analytical work has been done by economists on the proper scope of res judicata and the related notions of issue preclusion and waiver. We develop some simple points about these issues below, which provide some basis for questioning the refusal of the compliance Panel to entertain India's arguments on "non-attribution." Regarding the second issue, the Anti-dumping laws make so little economic sense in general that it is difficult to offer any guidance as to 
their "proper" administration. The ruling in favor of India on the presumption of dumping issue seems reasonable from a statistical standpoint, however, although it is less clear that it is right as a legal matter. Finally, the Appellate Body's deference to the factual conclusion of the Panel on the third issue raises no economic issues of note.

We lay out the legal issues and their resolution by the Panel and the Appellate Body in Section 2. Section 3 offers a critical analysis of the case from a law and economics perspective.

\section{Factual and legal issues and their disposition}

\subsection{Non-attribution of injury caused by "other factors"}

Article 3.5 of the Anti-dumping Agreement provides that investigating authorities must "examine any known factors other than the dumped imports which at the same time are injuring the domestic industry, and the injuries caused by these other factors must not be attributed to the dumped imports." In the original proceeding, India challenged the EC's duties, inter alia, on the grounds that the EC had failed to ensure that injury attributable to "other factors" was not attributed to dumped imports from India, although it did not pursue the issue very actively. The original Panel dismissed the one substantive point raised by India under this rubric, and otherwise said that India had failed to make out a prima facie case on the issue. That finding was not appealed.

The EC did not conduct a new analysis of "other factors" as part of its revised injury analysis when it promulgated Regulation No. 1644/2001, and had simply relied on its previous discussion of the matter. India then argued again that the EC had failed to ensure that injury caused by "other factors" was not attributed to dumped imports. In particular, it pointed to various "other factors" that had not been a subject of discussion before the original Panel, including rising input costs for European firms and the failure of output prices in the EC to keep up with inflation.

The EC requested a preliminary ruling from the Panel to the effect that such matters could not be raised in an Art. 21.5 proceeding, and the Panel agreed: "To rule on this aspect of India's claim under Article 3.5 in this proceeding would be to allow India a second chance to prevail on a claim which it raised, but did not pursue, in the original proceeding. We cannot conclude that such a result is required by 
Article 21.5 of the DSU, or any other provision. The possibility for manipulative or abusive litigation tactics that would be opened by allowing Members an opportunity to obtain a ruling in an Article 21.5 proceeding that they could have sought and obtained in the original dispute would, in our view, be inestimably harmful to the effective operation of the dispute settlement system."3 Although the Panel did not use these terms, its reasoning invokes notions of res judicata, issue preclusion, and waiver.

The Appellate Body affirmed the Panel's ruling on this issue. In doing so, it emphasized that new claims can at times be raised before an Art. 21.5 Panel. It noted that the purpose of such Panels is to review the WTO consistency of measures taken to comply with prior rulings, and that many such measures will differ significantly from the measures originally challenged, and may be inconsistent with WTO obligations in ways that the original measures were not. Although the Appellate Body made clear that new inconsistencies of this sort were the proper subject of discussion before an Art. 21.5 Panel, it stated: "[h]ere, India did not raise a new claim before the Art. 21.5 panel; rather, India reasserted in the Art. 21.5 proceedings the same claim that it had raised before the original panel in respect of a component of the implementation measure which was the same as the original measure. The same claim was dismissed by the original Panel, and India did not appeal that finding." 4 The Appellate Body went on to hold that when the original Panel report was adopted by the Dispute Settlement Body (DSB), it became a final resolution of the dispute on the "other factors" issue.

Like the Panel, the Appellate Body relied for its ruling not so much on any treaty text that addressed the issue, but on policy considerations and on its earlier decision reviewing a similar issue that had arisen before the Shrimp-Turtle compliance Panel. The Appellate Body emphasized that India had raised the "same" claim earlier and lost, and put less emphasis than the Panel had on the notion that the particular issues raised by India could have been raised before but were not.

\subsection{Injury due to exporters not individually investigated}

In the second investigation, as in the first, the EC did not investigate every Indian exporter of cotton-type bed linen. Article 6.10 of the Antidumping Agreement allows importing nations to investigate only

\footnotetext{
${ }^{3}$ Panel Rep. $\left\lceil 6.43 . \quad{ }^{4}\right.$ AB Rep. $\left\lceil 80 . \quad{ }^{5}\right.$ AB Rep. $\lceil 99$.
} 
a sample of all exporters in cases where an individual investigation of all of them would be "impracticable." Accordingly, the EC conducted individual investigations of five of the larger Indian exporters, and applied a weighted average anti-dumping duty to exports from other exporters as is allowed by Art. 9.4 of the Anti-dumping Agreement.

The most important change between the original investigation and the second was to eliminate the practice of "zeroing" in the computation of weighted average dumping margins. When zeroing was eliminated, two of the five exporters subject to individual investigation, accounting for $53 \%$ of the imports from the five individually investigated importers, were found not to be dumping at all. The issue before the compliance Panel was how this new finding should affect injury analysis by the EC.

Article 3.5 requires that the importing nation establish a causal link between the dumped imports and injury. In purporting to establish this link when promulgating Regulation No. 1644/2001, the EC assumed that all imports from Indian exporters not individually investigated had been dumped, even though $53 \%$ of the imports from the exporters individually investigated had not been dumped. India argued that the EC thereby violated Art. 3.1, which requires that the determination of injury be based on "positive evidence," including an "objective examination" of the "volume of dumped imports." India argued that the EC should presume that dumping was occurring by exporters not individually investigated in the same proportion as imports from exporters who were individually investigated (47\%). This would suggest a smaller volume of dumped imports than the EC had presumed were present, and might reverse the conclusion that dumped imports were causing material injury.

The EC argued that the presumption of dumping by exporters not investigated individually is permissible under the Anti-dumping Agreement. Its principal argument was based on Art. 9.4 of the Antidumping Agreement, which permits an anti-dumping duty to be imposed on exporters not individually investigated as long as it does not exceed "the weighted average margin of dumping established with respect to the selected exporters." The EC contended that because it was allowed to impose an anti-dumping duty on those exports, it had to also be allowed to consider them "dumped" for purposes of injury analysis. Next, it argued that the group of exporters that it had chosen to investigate individually were not selected to be a statistically valid sample, but rather represented the "largest percentage of the volume 
of the exports... which can reasonably be investigated," one of the options under Art. 6.10. Thus, the percentage of exports found to be dumped by the individually investigated exporters could not be assumed to reflect the amount of dumping by exporters not individually investigated.

The Panel agreed with the EC. "We can find no textual obligation in the AD Agreement to separate out the unexamined producers' imports into dumped and not-dumped for purposes of the injury analysis ..."6 It also found India's position to be logically flawed, given the fact that all non-investigated imports could be subjected to a positive anti-dumping duty under Art. 9.4: "Under India's approach, only a portion of imports from producers subject to that anti-dumping duty could be considered as 'dumped' for injury purposes. This effectively treats the imports from the same producers as dumped for purposes of duty assessment, and not dumped for purposes of injury analysis. In our view, this is an unacceptable outcome, suggesting that the analysis which leads to it is untenable."

The Appellate Body reversed. It emphasized the requirement for an "objective examination" of the volume of dumped imports, and noted that imports not sold at dumped prices were specifically enumerated in Art. 3.5 as one of the "other factors" which may cause injury and should not be attributed to dumped imports. It was also unpersuaded that imports from exporters not individually investigated could be presumed to be dumped simply because Art. 9.4 permits them to be subjected to an anti-dumping duty - "[w]e do not see why the volume of imports that have been found to be dumped by non-examined producers, for purposes of determining injury under paragraphs 1 and 2 of Article 3, must be congruent with the volume of imports from those non-examined producers that is subject to the imposition of antidumping duties under Article 9.4."7 The Appellate Body stopped short of endorsing India's proposed method for calculating the volume of dumped imports from exporters not individually investigated, however, allowing for the possibility that "positive evidence" of that volume might be based on something other than the percentage of exports dumped by the individually investigated exporters. ${ }^{8}$

Along the way, the Appellate Body was mindful of the standard of review under the Anti-dumping Agreement. Article 17.6(ii) of the

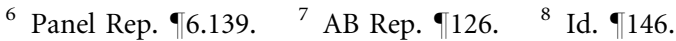


Agreement provides that " $[\mathrm{w}]$ here the panel finds that a relevant provision of the Agreement admits of more than one permissible interpretation, the panel shall find the authorities' measure to be in conformity with the Agreement if it rests on one of those permissible interpretations." The EC argued that its interpretation of the injury provisions was at least a "permissible" interpretation that was entitled to deference, but the Appellate Body disagreed: "[W]hatever methodology investigating authorities choose for calculating the volume of 'dumped imports,' that calculation and, ultimately, the determination of injury under Article 3, clearly must be made on the basis of 'positive evidence' and an 'objective examination.' These requirements are not ambiguous, and they do not 'admit of more than one permissible interpretation' within the meaning of the second sentence of Article 17.6(ii)." 9

\subsection{Consideration of all "relevant factors" bearing on injury}

Article 3.4 of the Anti-dumping Agreement requires importing nations to base their injury analysis on an examination of "all relevant economic factors... having a bearing on the state of the (domestic) industry." It then provides a non-exhaustive list of such factors. India asserted that the EC failed to gather data on and to evaluate two "relevant factors" - stocks and capacity utilization - when it promulgated Regulation No. 1644/2001. The EC asserted that such data had been presented before the investigative authorities, and had been properly considered. The Panel ruled for the EC on this point, and India argued that the Panel abused its discretion in doing so by, in effect, accepting the EC's unsupported assertions on the matter rather than conducting a more thorough investigation.

The Appellate Body upheld the Panel, which had "concluded that it was clear that the European Communities had 'in its record' information on stocks and capacity utilization - the two factors India had focused on - and that 'unlike the original determination, the EC's consideration of these factors [was] clearly set out on the face of the redetermination." 10 While India wished to characterize the Panel's conclusion as an abuse of its discretion, the Appellate Body saw it as a factual conclusion by the Panel that was within its proper discretion and should not be disturbed on appeal.

\footnotetext{
9 AB Rep. $\mid 118 . \quad 10$ AB Rep. 1154.
} 


\section{Critical analysis}

\subsection{Non-attribution and the procedural issue}

One can quibble with the willingness of the Appellate Body to permit the EC to rely on its original "other factors" analysis. In light of its resolution of the second issue in the case, discussed below, the EC is required to restate its assessment of the quantity of dumped imports, revising the estimate downward. The quantity of fairly traded imports, an "other factor" that might cause injury, must be revised upward. One might thus argue that the EC should redo both its analysis of harm attributable to "dumped imports" and its analysis of harm due to "other factors." The Appellate Body does not reach this conclusion, however, perhaps because India's arguments focused on EC input and output prices as the "other factors" to be considered.

The much more interesting aspect of the ruling on this issue, however, is its procedural implications. The WTO treaty text does not specifically address res judicata and related issues, leaving to Panels and to the Appellate Body the task of evolving sensible principles in the area. In this case, the Appellate Body insisted that "India did not raise a new claim before the Article 21.5 panel; rather, India reasserted in the Article 21.5 proceedings the same claim." At some level, it is difficult to quarrel with the proposition that parties to WTO disputes should not be permitted to relitigate the same claim over and over again. What the Appellate Body masks with this language, however, is that the concept of "sameness" can be interpreted broadly or narrowly.

Recall the facts: India had raised the "non-attribution" issue in its original complaint, but did not advance factual arguments in relation to that issue sufficient to make out a prima facie case. Then, before the compliance Panel, it sought to make those arguments seriously for the first time, pointing to "other factors" such as high EC input prices and low EC output prices. Here, to say that India had lost the same claim earlier is to imply that all arguments relating to a particular legal issue are part of the "same" claim, and are waived if they are omitted from the first round of litigation in which that issue appears. The Panel opinion hinted at an even broader principle when it stated that it would not afford India "an opportunity to obtain a ruling in an Article 21.5 proceeding that they could have sought and obtained in the original dispute." This language suggests that all legal issues that could have been raised in an earlier proceeding, but were not, are waived. For terminological simplicity, we refer to these principles as rules of waiver, 
although the reader should be aware that civil procedure treatises often attach the labels res judicata, issue preclusion, or claim preclusion to these types of rules.

Rules of waiver have the obvious consequence of encouraging litigants to raise issues sooner rather than later, and can hasten the final resolution of a dispute. Many legal systems have them. ${ }^{11}$ It is possible that such rules are economically desirable when all the costs and benefits of the legal system are taken into account, but that is not obvious. We have found no treatment of the issue in the existing law and economics literature on procedure, perhaps because a complete accounting of all the relevant considerations in any particular context is exceedingly difficult to provide. An exhaustive treatment is beyond the scope of this comment as well, but we will sketch some of the pertinent considerations that bear on the design of optimal waiver principles. Before addressing waiver, however, we set forth our understanding of the justification for res judicata in its narrower sense.

\subsubsection{Res judicata}

Compliance with the law generally has a social value, and the prompt resolution of legal proceedings can hasten valuable compliance. This observation seemingly applies as much to the WTO as to other legal contexts. But legal decision makers are imperfect, and may make errors in their findings of law or fact. When litigants are required to comply with erroneous decisions, error costs arise, often of the same nature as the gains from compliance with correct decisions. A desire to avoid errors motivates principles of "due process" in many legal systems. Process itself is costly, however, and so it is unrealistic for most legal systems to avoid error altogether. The task of designing an optimal procedure thus balances competing considerations: the value of resolving legal issues sooner and of reducing process costs on the one hand, against the costs of errors on the other.

Because of concerns about error, it is not uncommon for litigants to be permitted to raise issues more than once. The usual setting for revisiting issues is the "appeal," a common feature in many legal systems, including now the WTO. But there will generally be diminishing returns to reopening issues that have been previously

11 On the American rules in this area, see generally, Friedenthal, Kane and Miller (1999); James, Hazard and Leubsdorf (2001). 
decided - at some point, the likelihood of error becomes sufficiently small that the benefits of ending the dispute and the associated process costs predominate over any concerns about error. Thus, rights of appeal are always limited (and some matters may not be appealable at all).

Res judicata in its narrowest sense simply precludes a litigant raising an identical claim in a new proceeding when the claim was previously adjudicated. It can be understood as a presumption that the legal system in question already provides an appropriate error-correction mechanism through its appellate process. Once a litigant has raised an argument, lost, and exhausted all available appeals, no further delays and litigation costs are likely to be justified.

To be sure, scenarios may arise in which concern for error is particularly acute, and the limits on the process available in typical cases may appear too stringent. The usual solution to such problems, however, is for the legal system to add a more extensive appellate process for particular categories of cases rather than to permit tribunals to retreat from res judicata in its narrow form. Criminal defendants in the United States, for example, receive additional layers of appellate review not made available to civil litigants and capital defendants - because the costs of error are great and irreversible - are afforded procedural protections not made available to other criminal defendants.

\subsubsection{Waiver}

The rationale for rules of waiver must be somewhat different. By definition, waiver applies to arguments and issues that were not adjudicated previously but that could have been. There can be no presumption that their prior disposition was correct if there was no prior disposition.

But rules of waiver might be based on a related presumption - if a litigant did not bother to raise an argument previously, perhaps the litigant has revealed it to be weak, so that the likely error cost of ignoring it is small. Rules of waiver encourage litigants to bring all potentially meritorious arguments before the court at once so that the dispute can be resolved with dispatch and the gains from compliance with the law can be realized more quickly; any claims "waived" are presumed to be so weak that they need not be addressed.

This simple intuition may have much to do with the justification for doctrines of waiver, but it is incomplete for two reasons. First, to the degree that complainants internalize the costs of delay in bringing other parties' behavior into conformity with the law, the legal system 
seemingly has no interest in encouraging complainants to pursue compliance at a faster clip. Second, litigation becomes more expensive as more claims are brought. Each claim must be researched, briefed, and argued. Factual support must be amassed. Even if the adjudicative body can exercise "judicial economy" to avoid issues that need not be reached to resolve the case, the parties to the proceeding must still bear additional costs as the number of issues and arguments grows. Hence, if a complainant prefers to start with what it believes to be its strongest claims, and to leave others in abeyance should the initial claims fail, some of the costs of litigation (including some that are externalized) will be avoided if the initial claims succeed and resolve the dispute. This consideration, too, seems to argue for allowing the complainant to bring claims at its own pace, in preference to rules of waiver that penalize claimants for failing to bring issues before the dispute process at the outset.

An important countervailing consideration arises, however, if litigation exhibits economies of scale in relation to the number of claims in each proceeding. It seems quite likely that dispute proceedings have considerable fixed costs. For the WTO in particular, panelists must be selected and assembled for hearings. Each panelist will invest considerable time in learning the (often complex) background facts of the dispute. Many of these costs will be the same whether the dispute involves a single legal claim or many. And like other costs of litigation, a complaining nation does not bear all of these fixed costs.

The presence of considerable fixed costs to litigation can supply a positive externality to the consolidation of claims in an initial proceeding. Plausibly, a complainant might prefer to proceed more or less seriatim with its claims to save itself the variable costs of litigating matters that may prove unnecessary. But if considerable economies of scale are lost when the complainant proceeds in this fashion and those costs are borne by others, the system may gain by foreclosing such a strategy.

Of course, the mere existence of fixed costs is not sufficient to justify rules of waiver. Their magnitude must be considered in relation to the added variable costs of litigating more claims at once, claims that may prove unnecessary to litigate ex post. Roughly speaking, the greater the fixed costs of a proceeding in relation to the variable costs per claim, the stronger the case for insisting that more issues be raised at once.

These points also suggest the possibility of more refined waiver rules. Some types of claims may have very low marginal litigation costs, 
perhaps because they resolve themselves readily with reference to facts already in evidence. Others may require much additional fact-finding or investigation. Similarly, some claims may be legally straightforward, and others may be highly debatable and complex. The case for a rule of waiver is stronger with respect to the relatively cheaper factual and legal claims.

Likewise, the fixed costs of each proceeding may vary with the nature of the proceeding. With particular reference to Art. 21.5 compliance Panels, we note that these Panels are comprised of the same members as the original dispute Panel. Each panelist is presumably familiar with the facts and basic legal issues of the case already. Under these circumstances, it may make sense to have somewhat more lenient rules of waiver because the fixed costs of the second proceeding will tend to be smaller in relation to the variable costs of litigating more issues initially.

We note one further consideration that may have some bearing on rules of waiver. The compliance Panel in the Bed Linen case noted its concern for "manipulative and abusive" litigation tactics. It did not detail its fears in this regard, but its phrasing hints at concern for vexatious proceedings, brought not because of their potential legal merits but because of their capacity to harass the respondent. There is a considerable economic literature on the use of frivolous litigation to extract settlements, and it is possible that complainants in the WTO might hope to extract trade concessions in meritless cases from respondents anxious to avoid litigation costs. For such a strategy to justify rules of waiver, of course, it must be the case that litigation is more expensive seriatim than in a consolidated proceeding, presumably because of the fixed costs noted above - otherwise, vexatious claims brought all at once would be just as effective "harassment."

Although waiver rules may make vexatious litigation less troublesome in the presence of fixed costs, other procedural devices are better tailored to address the problem of vexatious claims. Parties who bring claims that are adjudged to be frivolous can be sanctioned in a variety of ways ("Rule 11 sanctions" in the parlance of American civil procedure). A potentially effective sanction is fee shifting, where the complainant must pay the litigation costs of the respondent. Such measures target frivolous litigation directly without affecting the timing of potentially meritorious claims. Hence, waiver rules are at most a "second-best" response to vexatious litigation. 


\subsubsection{Modeling the effect of waiver rules in the WTO}

Following the literature on efficient legal procedure, we would ideally like to model the problem of designing optimal rules of waiver. One would ask the question whether, in the absence of waiver rules, WTO complainants would bring too few claims at a time from a social standpoint. If so, one would then inquire whether waiver rules could correct the problem.

Such an analysis would be extremely complex, however, requiring attention to the social gains from litigation, the timing of those gains, and the magnitude and timing of litigation costs. The matter becomes all the more complicated in cases with multiple legal claims, in that the social returns to the proper adjudication of each claim may vary. Yet another complication is the fact that WTO litigants are governments. It is a commonplace in the procedure literature to treat litigants as expected profit maximizers, but governments cannot be presumed to behave in this fashion. Indeed, in WTO litigation, money rarely changes hands.

We thus limit ourselves to a very simple treatment of one piece of the puzzle that abstracts from these difficult issues. Our focus is on the question of how a rule of waiver affects the number of claims brought before the dispute resolution process, and thus the total variable costs of litigation.

Consider a two-period model. If the claimant wins at least one claim in period 1, it wins an award that it values at $B_{1}$. If it fails to win one claim in period 1 but wins at least one claim in period 2, it wins an award that it values at $B_{2}, B_{2}<B_{1}$. The difference between $B_{1}$ and $B_{2}$ reflects the cost to the claimant of delay in receiving the remedy. Assume that there are many potential arguments available to the claimant, and approximate these by a continuum of claims with measure $M$. The (small) claim $i$ has the (small) probability $p(i) \mathrm{d} i$ of success. It is brought at marginal cost $c(i) \mathrm{d} i$. It is optimal for the claimant to bring its "best" claims first; i.e. those with the highest $p(i) / c(i)$. Thus, we order the claims so that $p(i) / c(i)$ is a non-increasing function. Let $C(x)$ be the total cost of bringing the set of claims $[0, x] .{ }^{12}$

In a judicial system with waiver, the claimant must raise all arguments in a single "case." The case comprises the claims $[0, x]$, where $x$ is a decision variable for the claimant. In a judicial system without waiver, the claimant may return to the adjudicating body with additional claims

12 That is, $C(x)=\int_{0}^{x} c(i) \mathrm{d} i$. 
in period 2, if it fails to win at least one of its claims in period 1. In this setting, the claimant brings claims $\left[0, x_{1}\right]$ in period 1 and claims $\left[x_{1}, x_{1}+x_{2}\right]$ in period 2 (if there has been no success in period 1 ).

Let $F(x)$ be the probability that there is at least one successful claim from among those in $[0, x] ; F(0)=0, F(M) \leq 1$. The density, $f(x)$, is the probability that the first success comes on claim $x$. The hazard rate, $f(x) /[1-F(x)]$ is the probability that a success comes on $x$, given that there has been no success on any claims before $x$. Since the claims are independent, this is just $p(x)$. Bayes Rule tells us that the probability of at least one success before $x_{1}+x_{2}, F\left(x_{1}+x_{2}\right)$, is equal to the probability of at least one success before $x_{1}$ plus the probability of no successes before $x_{1}$ times the probability of at least one success between $x_{1}$ and $x_{2}$, or

$$
\begin{aligned}
F\left(x_{1}+x_{2}\right)= & F\left(x_{1}\right)+\left[1-F\left(x_{1}\right)\right] \times \\
& {\left[\operatorname{Pr}\left\{\text { at least one success between } x_{1} \text { and } x_{2}\right\}\right] }
\end{aligned}
$$

or

$$
\begin{aligned}
& \operatorname{Pr}\left\{\text { at least one success between } x_{1} \text { and } x_{2}\right\} \\
& =\frac{F\left(x_{1}+x_{2}\right)-F\left(x_{1}\right)}{1-F\left(x_{1}\right)}
\end{aligned}
$$

3.1.3.1 Judicial system with rule of waiver Here, the claimant must make any claims that it wishes to advance in the first period. The claimant chooses $x \geq 0$ to maximize

$$
F(x) B_{1}-C(x)
$$

The first order condition is

$$
f(x) B_{1}=c(x)
$$

that is, the claimant chooses the marginal claim $x$ to equate the probability that the first success will come on that claim times the award from winning the case to the marginal cost.

3.1.3.2 Judicial system without rule of waiver Here the claimant can spread claims over the two periods, coming back in period 2 if the claims brought in period 1 do not succeed. The claimant chooses 
$x_{1} \geq 0$ and $x_{2} \geq 0$ to maximize

$$
\begin{aligned}
F\left(x_{1}\right) B_{1} & +\left[1-F\left(x_{1}\right)\right]\left\{\frac{F\left(x_{1}+x_{2}\right)-F\left(x_{1}\right)}{1-F\left(x_{1}\right)}\right\} B_{2} \\
& -C\left(x_{1}\right)-\left[1-F\left(x_{1}\right)\right]\left[C\left(x_{1}+x_{2}\right)-C\left(x_{1}\right)\right]
\end{aligned}
$$

Here, the first term is the probability of success in the first case times the first period award. The second term is the probability of no success in the first case times the probability of at least one success from among claims $\left[x_{1}, x_{1}+x_{2}\right]$ (see above) times the reward from a victory in case 2 . The third term is the total cost of the first case. The last term is the incremental cost of the second case multiplied by the probability of a second case.

The first order conditions are:

$$
\begin{aligned}
f\left(x_{1}\right)\left(B_{1}-B_{2}\right) & +f\left(x_{1}+x_{2}\right) B_{2}-f\left(x_{1}\right) C\left(x_{1}\right)-F\left(x_{1}\right) c\left(x_{1}\right) \\
& -\left[1-F\left(x_{1}\right)\right] c\left(x_{1}+x_{2}\right)+f\left(x_{1}\right) C\left(x_{1}+x_{2}\right)=0
\end{aligned}
$$

and

$$
f\left(x_{1}+x_{2}\right) B_{2}-\left[1-F\left(x_{1}\right)\right] c\left(x_{1}+x_{2}\right) \leq 0,
$$

where expression (2) holds with equality if and only if $x_{2}>0$. Assume that it is profitable to bring a second case, which requires a sufficiently large $B_{2}$ (if a second case is not profitable, a rule of waiver has no effect). Then $f\left(x_{1}+x_{2}\right) B_{2}-\left[1-F\left(x_{1}\right)\right] c\left(x_{1}+x_{2}\right)=0$, which we can substitute into expression (1) to obtain

$$
f\left(x_{1}\right)\left(B_{1}-B_{2}\right)-f\left(x_{1}\right) C\left(x_{1}\right)-F\left(x_{1}\right) c\left(x_{1}\right)+f\left(x_{1}\right) C\left(x_{1}+x_{2}\right)=0 .
$$

3.1.3.3 An example Consider the case of a constant hazard rate, which arises when the probability of success in each claim is the same. Then $F(x)=1-\mathrm{e}^{-\lambda x}$ for some $\lambda>0$. Suppose also that every claim has the same cost, so that $c(x)=c$ and $C(x)=c x$. All claims are symmetric under these assumptions, but there are still diminishing returns to filing more and more claims, and the claimant generally will not file all of them. 
3.1.3.4 The example with waiver The first order condition becomes

$$
\lambda \mathrm{e}^{-\lambda x} B_{1}=c
$$

or

$$
\mathrm{e}^{\lambda x}=\frac{\lambda B_{1}}{c} .
$$

For convenience, define $\theta_{i}=\lambda B_{i} / c$, so the last expression can be written as

$$
\mathrm{e}^{\lambda x}=\theta_{1} \quad \text { or } \quad x=\log \theta_{1} / \lambda
$$

3.1.3.5 The example with no rule of waiver If $x_{2}>0$, then expression (2) implies

$$
\lambda \mathrm{e}^{-\lambda\left(x_{1}+x_{2}\right)} B_{2}=\mathrm{e}^{-\lambda x_{1}} c
$$

or

$$
\mathrm{e}^{\lambda x_{2}}=\frac{\lambda B_{2}}{c}=\theta_{2}
$$

Taking logs, $x_{2}=\log \theta_{2} / \lambda$.

Now, for the choice of $x_{1}$, expression (3) becomes

$$
\lambda \mathrm{e}^{-\lambda x_{1}}\left(B_{1}-B_{2}\right)-\lambda \mathrm{e}^{-\lambda x_{1}} c x_{1}-\left(1-\lambda \mathrm{e}^{-\lambda x_{1}}\right) c+\lambda \mathrm{e}^{-\lambda x_{1}} c\left(x_{1}+x_{2}\right)=0
$$

or

$$
c \mathrm{e}^{\lambda x_{1}}=\lambda B_{1}-\lambda B_{2}+c\left(1+\log \theta_{2}\right),
$$

where this last expression uses $\lambda x_{2}=\log \theta_{2}$ from the solution for $x_{2}$. We can now write

$$
\mathrm{e}^{\lambda x_{1}}=\theta_{1}-\left(\theta_{2}-1-\log \theta_{2}\right) .
$$

The term in parentheses is positive for all $\theta_{2}>1$ (and unless $\theta_{2}>1, x_{2}=0$ ). Thus, comparing the solution for the case with a rule of waiver, the claimant files more claims in the first round under a rule of waiver than without waiver, as one might expect.

Note further that

$$
\mathrm{e}^{\lambda\left(x_{1}+x_{2}\right)}=\mathrm{e}^{\lambda x_{1}} \cdot \mathrm{e}^{\lambda x_{2}}=\theta_{2}\left(\theta_{1}-\theta_{2}+1+\log \theta_{2}\right),
$$


thus

$$
\mathrm{e}^{\lambda\left(x_{1}+x_{2}\right)}-\theta_{1}=\left(\theta_{1}-\theta_{2}\right)\left(\theta_{2}-1\right)+\theta_{2} \log \theta_{2}>0
$$

which implies that the total number of claims filed in the two cases without a rule of waiver (if the second case is necessary) exceeds the number of claims that will be filed in a single case under a rule of waiver.

Finally, consider the expected number of claims brought under each regime. With no rule of waiver, expected claims are $x_{1}+\left[1-F\left(x_{1}\right)\right] x_{2}=x_{1}+\mathrm{e}^{-\lambda x_{1}} x_{2}$. Using the results above, this expression becomes

$$
\frac{\log \theta_{2}}{\lambda\left(\theta_{1}-\theta_{2}+1+\log \theta_{2}\right)}+\frac{\log \left(\theta_{1}-\theta_{2}+1+\log \theta_{2}\right)}{\lambda} .
$$

This expression can be greater or smaller than the solution for $x$ (the expected and actual number of claims) under a rule of waiver, $\log \theta_{1} / \lambda$. We have evaluated the difference numerically, and find that its sign depends on the sizes of the two parameters, $\theta_{1}$ and $\theta_{2}$.

For example, setting $\theta_{1}=3$ and allowing $\theta_{2}$ to vary over its full possible range (from 1 at the lowest, given that $x_{2}$ positive requires $\theta_{2}>1$, to 3 at the highest, since $\theta_{1}>\theta_{2}$ ), we find that the difference rises steadily from zero. In this case, the expected number of claims without a rule of waiver is higher for all $\theta_{2} \in(1,3]$, and the difference is larger the greater $\theta_{2}$ is. This suggests that a rule of waiver will reduce the variable costs of litigation.

But when $\theta_{1}=5$, a somewhat different picture emerges. The difference between the expected number of claims without and with a rule of waiver rises above zero as $\theta_{2}$ rises initially, but it reaches a maximum and turns negative as $\theta_{2}$ approaches $\theta_{1}$. And when $\theta_{1}=10$, the difference is negative for all $\theta_{2}$ above approximately 4.0, so that the expected number of claims with a rule of waiver can clearly exceed the number without a rule of waiver for some parameter values. In particular, when $\theta_{1}$ is "high" and the cost of delay is not too great $\left(\theta_{1}-\theta_{2}\right.$ is not too big), a rule of waiver actually increases the expected number of claims filed.

The explanation for these findings is rather subtle. Fix $\theta_{1}$ and consider an increase in $B_{2}$, which increases $\theta_{2}$. Clearly, this has no effect on the number of claims brought in a regime with a rule of waiver. When there is no rule of waiver, an increase in $\theta_{2}$ reduces the number of claims brought in a first case, but it increases both the probability that there 
will be a second case and the number of claims brought in such an event. The net effect on the expected number of claims can be positive or negative. We calculate that an increase in $\theta_{2}$ actually decreases the expected number of claims in a regime without a rule of waiver if and only if $1+\left(\theta_{1}-\theta_{2}\right)\left(2-\theta_{2}\right)-\left(\theta_{2}-1-\log \theta_{2}\right)<0$. If $\theta_{1}-\theta_{2}$ is small (little cost of delay), this inequality is satisfied for $\theta_{2}>2+\log \theta_{2}$; i.e. $\theta_{2}$ greater than approximately 3.15. Thus, when $\theta_{1}$ and $\theta_{2}$ are both large and the difference is small, the expected number of claims in a system without a rule of waiver is relatively small compared to the large number of arguments that the claimant brings with a rule of waiver.

Our results are only the beginning of a full treatment of the issues for reasons noted earlier - we have not modeled the social returns to litigation or any litigation cost externalities. But even the modest piece of the problem that we explore is quite complex, as the reader will no doubt have noticed. We can offer little definitive advice other than to urge caution in the evolution of rules of waiver in the WTO (and more generally). It is not at all obvious that social welfare will improve if tribunals insist that claimants bring all claims to an initial proceeding lest they be waived. Particularly when the fixed costs of additional proceedings are modest, it may be better to proceed on the strongest claims first and then to litigate others later only if necessary. And because the fixed cost aspects of Art. 21.5 compliance Panels may tend to be relatively modest, special caution is appropriate there. Compliance Panels should perhaps employ a rather narrow conception of what constitutes the "same" claim when following the Appellate Body's directive to deny claimants a second bite of the apple.

Returning to the facts of the Bed Linen case, it is not obvious to us that India's failure to develop its case fully on the non-attribution issue during the first proceeding should have precluded it from raising the issue again in the compliance proceeding. Its arguments regarding "other factors" such as EC input and output prices had not been vetted earlier, nor is it clear that the EC would have suffered any serious prejudice if forced to address them before the Art. 21.5 Panel. The decision by the Panel and the Appellate Body to foreclose those arguments may encourage WTO litigants to throw the "kitchen sink" into their initial complaints and arguments, so that initial Panel proceedings become even more (and perhaps unduly) cumbersome. This is particularly true if, as we imagine being the case, the rules of res judicata and waiver that apply before compliance Panels will apply 
more generally within the system, and bar the filing of new claims relating to the same facts when an initial set of claims proves unsuccessful.

\subsection{Injury caused by exporters not individually investigated}

From an economic perspective, we agree with the Appellate Body that if only $47 \%$ of the goods from the Indian exporters actually investigated were dumped, it is most unlikely that $100 \%$ of the goods from exporters not investigated were dumped. It is also clear from the Antidumping Agreement that fairly traded imports constitute one of the "other factors" that may cause injury to an industry, and that such injury should not be attributed to dumped imports. To allow the EC to presume that all exporters not investigated were dumping under these circumstances would almost certainly inflate the quantity of "dumped imports" above its true value, and might in theory produce an erroneous finding that material injury resulted from dumping.

We nevertheless have one reservation about the ruling in India's favor on this issue. The Panel was persuaded by the argument that India's position implies an odd lack of parallelism in the Anti-dumping Agreement between the imports that are considered dumped for purposes of injury analysis, and the imports that are considered dumped for purposes of duty collection. The Appellate Body found this disjunction less jarring, and we might agree if the issue was simply one of construction in the face of textual ambiguity. But, as noted earlier, the Anti-dumping Agreement contains a special standard of review Art. 17.6(ii), which requires deference to national implementation of WTO law that rests on a "permissible" interpretation. The Appellate Body's suggestion that the terms "positive evidence" and "objective examination" are not ambiguous, and do not "admit of more than one permissible interpretation," is a bit facile. The EC position is essentially that, in defining the quantity of "dumped imports," it can rely on the "objective evidence" provided by the set of imports to which antidumping duties may apply. We are hard pressed to conclude that such an interpretation of the Agreement is not "permissible."

\subsection{Deference to the panel on the "relevant factors" issue}

The Appellate Body's deference to the Panel on the question of whether the EC considered all "relevant factors" in its injury analysis raises no issues of note. Deference to the "trier of fact" on factual issues is routine 
in many legal systems, and is certainly a central tenet of appellate review in the WTO. Absent a showing of bias or abuse by India, the Appellate Body presumed that the Panel had satisfied itself on this essentially factual question, and would not allow the issue to be revisited under the guise of an argument that the Panel failed to make an adequate investigation as a "procedural" matter. We can imagine cases where a Panel might so clearly fail in its duties to investigate factual issues that a reversal of its findings might be warranted, but here, India did not make enough of a showing to convince the Appellate Body, and we would have no basis for second guessing that judgment.

\section{References}

Friedenthal, J. H., Kane, M. K. and Miller, A. R. (1999). Civil Procedure 3rd Edn. (Minneapolis: West).

James, F., Hazard, G. C. and Leubsdorf, J. (2001). Civil Procedure 5th Edn. (New York: Foundation).

Janow, M. E. and Staiger, R. W. (2003). European Communities - Anti-Dumping Duties on Imports of Cotton-Type Bed Linen from India. In H. Horn and P. C. Mavroidis, eds., The WTO Case Law of 2001, pp. 115-139 (Cambridge: Cambridge University Press). 